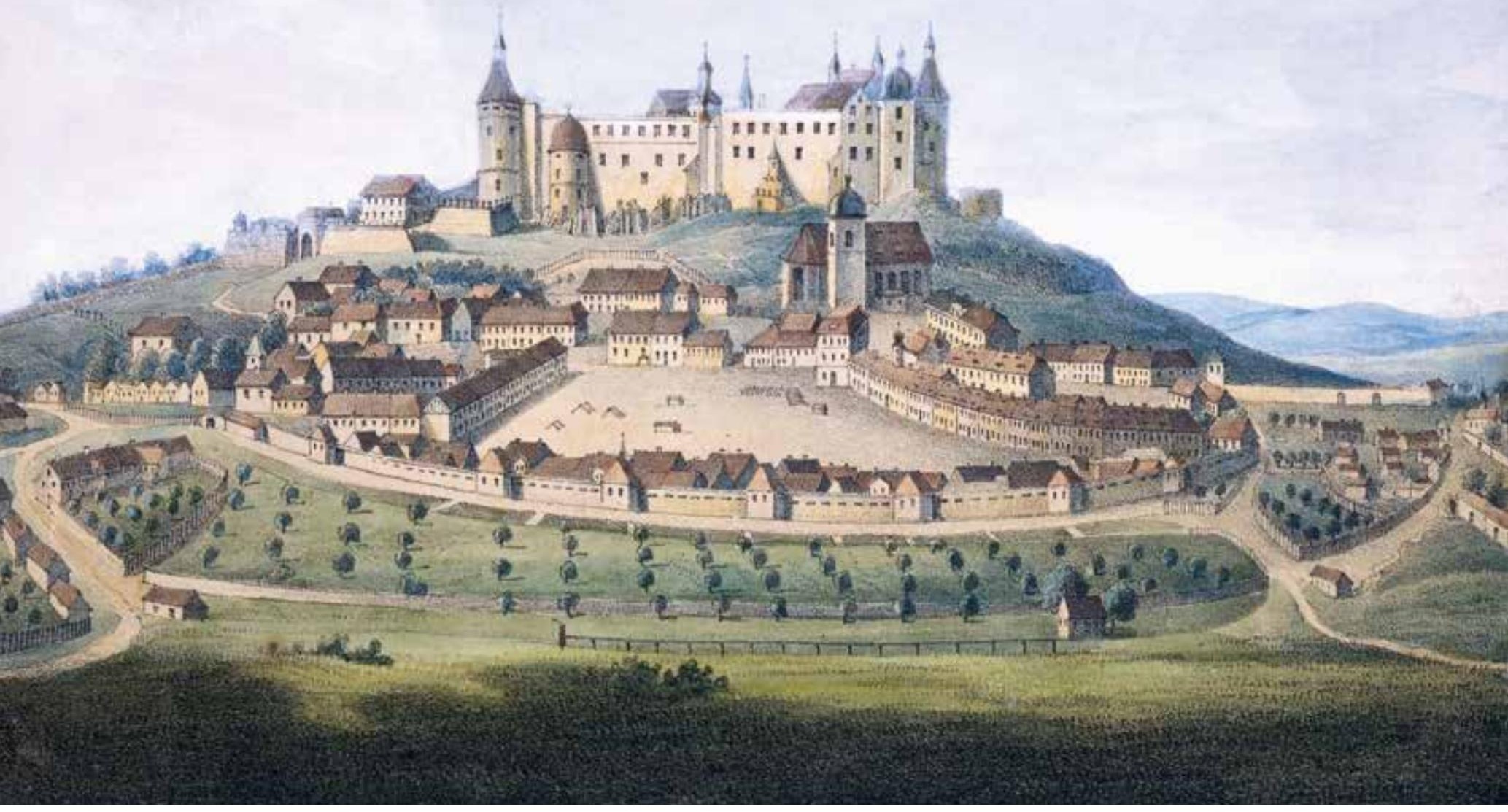

\title{
Das Hochstift Meißen vor der Reformation
}

\author{
Uwe Ulrich Jäschke, Matthias Donath
}

Stolpen war bis 1559 die Hauptresidenz der Bischöfe von Meißen. Das unterhalb der Burg gelegene Städtchen hieß ursprünglich Jochgrim. Kolorierte Ansicht aus der Mitte des 19. Jahrhunderts nach einer Vorlage von 1758

1 Karlheinz Blaschke/Uwe Ulrich Jäschke: Kursächsischer Ämteratlas 1790. Chemnitz 2009.

2 Joachim Huth: Der Besitz des Hochstifts Meißen. In: Franz Lau (Hrsg.): Das Hochstift Meißen. Aufsätze zur sächsischen Kirchengeschichte. Berlin 1973, S. 77-98; André Thieme: Herrschaft und Amt Stolpen in der Hand der Bischöfe von Meißen. In: Monumenta Misnensia. Jahrbuch für Dom und Albrechtsburg zu Meißen 6 (2003/ 2004), S. 114-127.
Der Begriff „Hochstift“ bezeichnet den weltlichen Besitz eines Bischofs - und damit jenes Land, in dem der Bischof in seiner Eigenschaft als Reichsfürst die Landesherrschaft ausübte. „Hochstift" kennzeichnet demnach einerseits eine Institution, andererseits ein Territorium. Heute ist das Hochstift Meißen eine kirchliche Einrichtung, die man nicht mit einem bestimmten Territorium verbindet, denn das zuletzt verbliebene zugehörige Land ist im 19. Jahrhundert in das Königreich Sachsen integriert worden. Weil die territoriale Bedeutung des Hochstifts Meißen selbst unter Geschichtskundigen kaum bekannt ist, erstellte Prof. Dr. Uwe Ulrich Jäschke (HTW Dresden) nach Entwurf von Dr. Matthias Donath die nachfolgende Karte. Sie zeigt den Gebietsstand des Hochstifts Meißen um das Jahr 1500 dorfgenau an.

Die Karte beruht auf dem Kursächsischen Ämteratlas von $1790^{1}$ und Einzelforschungen zur Entstehung und Entwicklung des Besitzes der Meiß- ner Bischöfe ${ }^{2}$. Dabei mussten bei der Übertragung ins Kartenbild Vereinfachungen vorgenommen werden. Die Herrschaftsrechte in den einzelnen Dörfern waren vielfach zersplittert. Dem Bischof von Meißen konnten zum Beispiel nur Teile eines Dorfes oder nur einzelne Bauern gehören, oder er bezog nur bestimmte Abgaben aus einem Dorf. Diese Detailinformationen ließen sich in der flächendeckenden Übersichtsdarstellung nicht abbilden. Zumindest für das Amt Stolpen liegt aber eine Detailkarte vor, die den Besitzstand um 1500 sehr differenziert wiedergibt. ${ }^{3}$

Das Hochstift Meißen war ein geistliches Reichsfürstentum, in dem der Bischof von Meißen die Landeshoheit ausübte und aus dem er Einnahmen bezog, die er persönlich nutzen konnte. Verfassungsrechtlich war das Hochstift Meißen eine Wahlmonarchie, denn die Landesfürsten, also die Bischöfe, wurden vom Domkapitel gewählt. Eine dynastische Herrschaftsweitergabe war nicht vorgesehen und nicht möglich. Als Reichsfürsten hat- 
ten die Bischöfe Sitz und Stimme auf der Geistlichen Bank des Reichstags. Die Reichsstandschaft der Bischöfe ist allerdings von den Wettinern bestritten und negiert worden. Seit dem 14. Jahrhundert versuchten sie, die Bischöfe von Meißen $\mathrm{zu}$ mediatisieren. Ihnen gelang zwar eine weitgehende Integration des Hochstifts Meißen in den wettinischen Hegemonialraum, nicht aber eine Auflösung des Reichsfürstentums. Es blieb formal bis zum Ende des Alten Reichs bestehen; die letzten Hoheitsrechte wurden erst 1831 aufgehoben. Das Wappen des Hochstifts Meißen lässt sich erstmals im 14. Jahrhundert nachweisen. Es zeigt das Lamm Gottes mit der Siegesfahne vor rotem Grund. Das Lamm Gottes (Osterlamm) ist ein Symbol für Jesus Christus, der die Sünde der Welt trägt und in der Auferstehung den Tod überwunden hat. Warum dieses Wappenbild für das Hochstift Meißen gewählt wurde, lässt sich nicht schlüssig erklären, weil ein unmittelbarer Bezug zu Meißen und zu den Bistumsheiligen fehlt; das Motiv ist in der kirchlichen Heraldik aber durchaus geläufig. Die Bischöfe kombinierten das Wappen des Hochstifts mit ihrem Familienwappen. Das Wappen war dann lange nicht in Gebrauch, wird aber heute wieder verwendet. Das Domkapitel legte dazu am 31. Oktober 2016 eine amtliche Fassung fest. ${ }^{4}$

Das Territorium des Hochstifts Meißen bildete sich zwischen dem späten 10. Jahrhundert und der Mitte des 14. Jahrhunderts heraus. Dabei entstand kein geschlossenes Territorium, sondern ein zersplittertes Gebilde aus separaten Gebietsteilen. Die beiden größten zusammenhängenden Territorien waren das Amt Stolpen mit zahlreichen Dörfern um Stolpen und Bischofswerda und im Gebiet südlich von Bautzen sowie das Amt Wurzen. Hinzu kam Streubesitz bei Dresden, um Mügeln und bei Belgern. Die älteste Erwerbung war das Dorf Boritz an der Elbe, das im Jahr 979 zusammen mit dem Elbzoll zwischen Meißen und Belgern an das Hochstift Meißen kam. Der Besitz in der Oberlausitz gründet sich auf eine Schenkung des deutschen Kaisers Heinrich II., der dem Bischof von Meißen 1006 die Burgwarde Göda, Doberschau und Dolgowitz vermachte. Wurzen ist vermutlich im frühen 11. Jahrhundert an die Bischöfe gelangt; der Burgward Püchau an der Mulde kam 1040 dazu. Ausgehend von diesen Besitzkernen, betrieben die Bischöfe von Meißen einen gezielten Landesausbau. Sie gründeten Dörfer wie Kühren bei Wurzen ${ }^{5}$ oder Bischdorf bei Löbau und zu Beginn des 13. Jahrhunderts die Stadt Bischofswerda. Vor 1227 erwarb Bischof Bruno die Burg Stolpen ${ }^{6}$; spätestens 1249 beherrschten die Bischöfe die Stadt Mügeln und ihre Umgebung. 1336 kam Liebethal in den Besitz der Bischöfe. Gleichzeitig gingen zahlreiche Gebietsteile an andere Herrschaftsträger verloren, etwa der Gau Zagost („hinter dem Wald“) um Ostritz und Seidenberg in der östlichen Oberlausitz, die Stadt Pirna, Stadt und Schloss Nossen oder die Besitzungen an der Mulde um Löbnitz.
Das zersplitterte Territorium des Hochstifts Meißen hatte keinen städtischen Zentralort. Meißen selbst lag nicht im Hochstift Meißen.

Die Landeshoheit der Bischöfe von Meißen im Hochstift Meißen bedeutete nicht, dass die Bischöfe auf alle Einnahmen aus den Städten und Dörfern zurückgreifen konnte. Vielmehr waren Besitzungen und Herrschaftsrechte an Vasallen verlehnt. Die Rittergüter befanden sich in der Hand meißnischer Adelsfamilien. Das Hochstift Meißen hatte einen Lehnhof, der die Belehnungen vornahm; erhalten ist das Lehnbuch Johanns von Salhausen mit Eintragung aller Belehnungen zwischen 1488 und $1518 .^{7}$ Nicht verlehnt waren die Bischofsschlösser, mehrere Wirtschaftshöfe sowie die vier Städte Stolpen (ehemals Jochgrim), Bischofswerda, Mügeln und Wurzen, über die der Bischof die Stadtherrschaft ausübte.

Vom Hochstift Meißen ist der Besitz des Domkapitels zu unterscheiden. Er konzentrierte sich im Raum um Meißen und Dresden. Diese Dörfer gehörten nicht zum Hochstift Meißen, sondern waren Teil des wettinischen Herrschaftsgebiets. Die Landeshoheit lag bei den Markgrafen von Meißen bzw. Kurfürsten und Herzögen von Sachsen. Das Meißner Domkapitel übte aber die Grundherrschaft aus und bezog die Abgaben und Frondienste der dienstpflichtigen Bewohner. Der Grundbesitz war seit dem 11. Jahrhundert als Stiftungsgut an das Domkapitel gelangt. Dieses nutzte die Dörfer und ihre Erträge, um Präbenden (Pfründen) auszugeben. Die Erträge einiger Dörfer, der sogenannten Baumeistereidörfer, kamen der Baumeistereikasse zugute. Aus ihr wurde nicht nur die Unterhaltung des Meißner Doms finanziert, sondern auch zahlreiche baufremde Aufgaben. $^{8}$

Der Verlust des Grundbesitzes nach Einführung der Reformation soll hier nur in groben Zügen skizziert werden. 1559 wurde Bischof Johann IX. von Haugwitz (1524-1595) gezwungen, das Amt Stolpen an Kurfürst August von Sachsen (15261586) abzutreten. Das ermöglichte die Einführung der Reformation in diesem Teil des Bischofslandes. Der Bischof wurde mit Stadt, Dorf und Kloster Mühlberg abgefunden, wo sich die Reformation längst durchgesetzt hatte. 1570 vertauschte er Mühlberg gegen die Stadt Belgern und den Besitz des früheren Klosters Sornzig. Das Hochstift Meißen bestand seitdem nur noch aus dem Stiftsamt Wurzen (mit Streubesitz bei Belgern), dem Amt Mügeln und dem Klosteramt Sornzig. Zur Verwaltung dieses Gebiets war eine Stiftsregierung mit Sitz in Wurzen eingerichtet worden. Das Meißner Domkapitel musste ab 1560 einen Teil seines Grundbesitzes an Kurfürst August abtreten. Dieser gründete das Prokuraturamt Meißen, auf dessen Erträge das Domkapitel keinen Zugriff mehr hatte. Es behielt rund 20 Dörfer und Dorfanteile, die im Stiftsamt Meißen zusammengefasst waren. Die Agrarreformen im 19. Jahrhundert führten zum vollständigen Verlust des Grundbesitzes.

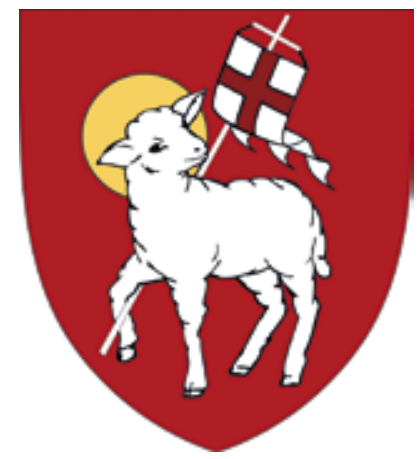

Wappen des Hochstifts Meißen in der 2016 festgelegten Fassung (c) Hochstift Meißen

3 Thieme 2003/2004 (wie Anm. 2), Kartenbeilage.

4 Vgl. Matthias Donath: Wappen und Siegel des Hochstifts Meißen. In: Monumenta Misnensia. Jahrbuch für Dom und Albrechtsburg zu Meißen 13 (2017/2018), S. 4-17.

5 Die Kührener Urkunde von 1154 ist ein wichtiges Dokument der hochmittelalterlichen Ostsiedlung, vgl. Enno Bünz (Hrsg.): Ostsiedlung und Landesausbau in Sachsen. Die Kührener Urkunde von 1154 und ihr historisches Umfeld. Leipzig 2008.

6 Lars-Arne Dannenberg: Mit Schwert und Krummstab. Beobachtungen zum bischöflich-meißnischen Landesausbau in der Oberlausitz unter Bischof Bruno von Porstendorf (1209/10-1228). In: Lars-Arne Dannenberg/ Dietrich Scholze (Hrsg.): Stätten und Stationen religiösen Wirkens. Bautzen 2009, S. 57-110.

7 Archiv des Domstifts Wurzen, Nr. 33, vgl. Matthias Donath/Lars-Arne Dannenberg/ Alexander Wieckowski: Bischof Johann VI. von Meißen (1444-1518) und die Familie von Salhausen in Sachsen und Böhmen. In: Sächsische Heimatblätter 64 (2018), S. 123-142, hier S. 140, Anm. 3

8 Zum Grundbesitz des Meißner Domkapitels in der Lommatzscher Pflege vgl. Matthias Donath: Zur Verwaltungsgeschichte der Lommatzscher Pflege. In: Sächsische Heimatblätter 63 (2017), S. 311-318. 

